\title{
Leading Innovation: the theoretical basis and connotation
}

\author{
Haibing Liu ${ }^{1 \mathrm{a} *}$ Lei Yang $^{1 \mathrm{~b}}$ \\ School of Economics and Management Lanzhou Jiaotong University Lanzhou, China \\ $\mathrm{a}^{*}$ Corresponding author: habliu@zju.edu.cn \\ byangleilei2588@163.com
}

\begin{abstract}
The concept of Leading Innovation is tentatively defined from four dimensions: Value, Attitude, Effect and Driving (VERD). The value orientation of innovation-leading is beyond the satisfaction of enterprises' own interests and values. It is committed to the dual balance between enterprises' own interests and the promotion of social interests, and attaches more importance to the realization of their own interests during the process of promoting social progress. Leading Innovation leads innovation to a higher level, which requires a stronger sense of social responsibility as the guidance, in an innovative way to "guide, leading" the choice and implementation of corporate strategy, so as to achieve positive interaction between the value of enterprise benefits and social value, promote the progress of human society; In addition to building sustainable competitive advantages of enterprises, the effect of innovation-leading is more important because of its contribution to industrial technology and social progress; The driving force of innovation is innovation culture.
\end{abstract}

\section{INTRODUCTION}

Innovation-driven is a means to achieve enterprise goals in the strategic management paradigm, which refers to the establishment of sustainable competitive advantage through innovation, and the Leading Innovation means that it is necessary to transform the practice of strategic orientation to build enterprise advantage into innovation orientation constructs the power of enterprise sustainable development. Innovation is the basic logic and value orientation of enterprise development, the Innovation is not only the starting point of enterprise behavior, is also the end. And this has both similarities and differences with the strategic management theory which started in the 1960 s, formally formed in the 1970s, flourished in the 1980 s and 1990 s, fission in the 21 st century in the 10th century. It can be said that from the macro level, "Leading Innovation" is replacing the traditional strategic orientation, which is a problem of the development paradigm of the enterprise level. From the micro level, it is to further enhance the importance of innovation-driven, and forming the "Leading Innovation", which has arrived a higher level than the strategic orientation.

Contrast "Leading Innovation" and "strategic orientation", it is not difficult to found that there is a compatibility between "strategic orientation of innovation" and "strategic orientation of innovation", but also exist obvious theoretical distinction, (1) "Leading Innovation" is a circular closed-loop of enterprise behavior with innovation as the axis, while "strategic orientation" is a strategic analysis and "strategic orientation" is to analyze and select enterprise behavior on the axis of strategy; (2) "Leading Innovation" takes innovation as the primary driving force, while "strategic orientation" emphasizes the guiding role of strategy. Obviously, the existing strategic management theory and analytical paradigm cannot fully and effectively carry out the dialogue with "Leading Innovation", so it is urgent to build the theoretical framework of "Leading Innovation" for enterprises. However, there is still a lack of theoretical literature on "Leading Innovation". Based on the above analysis, this paper deeply explores the theoretical basis and connotation of leading innovation, and establishes the conceptual mechanism of "Leading Innovation".

\section{THEORY}

Compared with the strategic view, the word "innovation" is much earlier than the word "strategy". So far, there are quite a lot of literatures discussing the problems of enterprise innovation and innovation management. However, a standardized and systematic "innovation view" has not yet been formed. Let's just call it "innovation view", which is helpful for us to sort out the literature of innovation with the progressive logic of innovation research and make it systematic. It can be roughly sorted into four development stages:

\section{A. The "innovation view": As an idea}

The idea of innovation emerged in the 1930s. J.A. schumpeter first proposed the concept of "innovation" in 1934, believing that innovation was an unprecedented "new combination" of factors of production and conditions that could be introduced into the production 
system. In schumpeter's innovation theory, innovation is regarded as an idea to drive economic development, and the overall picture of innovation is drawn, which has a positive and profound impact on the subsequent innovation research. However, it can be seen that innovation belongs to economic development and is the explanatory variable of economic development, while economic development is the target variable of innovation. But limited to the historical background, these early theories about innovation are more reflected as an idea.

\section{B. The "innovation view": As a element}

Since schumpeter put forward the concept of "innovation", the role of innovation to the development of enterprises has been paid more and more attention. The research on innovation gradually deepens from the original simple means to the elements. This is closely related to the development of the industrial revolution, especially in the era of the Third and Fourth Industrial Revolutions, the contribution of innovation to organizational performance has exceeded the traditional management functions, and innovation is the key to establish the relative competitive advantage of enterprises in the industry (Liu haibing, 2018 [2]).

Taking innovation as an element means that innovation is separated from the five elements of "plan, organization, command, coordination and control" in fayol's era relatively independently, and its connotation, structure and mechanism are gradually filled and enriched. Research on innovation mainly covers technology innovation (Dosi G., 1982 [3]), organizational innovation, culture innovation and collaboration innovation (Ulrich,Lichtenaler, 2013) and Total Innovation Management (xu qingrui, 2007 [4]). This research paradigm has made a pioneering study of the relatively grand proposition of innovation from the micro mechanism, and exerted an important influence on the academic circle and management practice, and So far, it still shows strong vitality.

\section{The "innovation view": As a methodology}

With the continuous enrichment of innovation implications and mechanisms, under the increasingly uncertain environment, "how to implement innovation" and "what kind of innovation is needed" to the core competitiveness of enterprises have become the focus of researchers' interest, which has roughly formed methodological innovation in two directions.

First, technological distance is the standard. Radical innovation (Leifer et al., 2000), disruptive innovation (Christensen and Raynor, 2003[5]), breakthrough innovation (Hargadon, 2003[6]), major innovation (O'connor, 2008 [7] ), discontinuous innovation and other theories emerged successively, which maintain internal unification in these theories, that is, enterprises can obtain leading competitive advantage by maintaining a significant technological distance with competitors (Seigyoung Auh, and Peter Yannopoulos, 2014). In contrast, there is another type of innovation based on continuous technological innovation and upgrading of organizational knowledge, such as incremental innovation and continuous innovation.
Secondly, Based on the boundary of innovation, the discussion of closed innovation and open innovation has appeared. collaboration innovation and the user innovation prior to the concept of open innovation. Open innovation was proposed by Chesbrough (2003) [8], consider that under the background of the rapid development of information technology, knowledge staff fast flow, industry life cycle shorten, accelerating technology innovation, enterprises can get more external resources by opening their borders. In this way, innovation efficiency can be improved on the basis of integrating internal and external innovation resources.

\section{The "innovation view": As a value}

Different from the concept of innovation in the first three development stages, the concept of innovation in this stage starts to break the shackles of the enterprise boundary and seek the balance of value in the symbiotic relationship between the society and the enterprise, that is, to discuss not only the value contribution of the enterprise's innovation to the enterprise itself, but also the positive value effect to the society. The most influential and representative are inclusive innovation and responsible innovation.

Inclusive innovation stems from the concept of inclusive growth at the Asian Development Bank in 2007. Later, George (2012)and other scholars introduced this concept into enterprise development, gradually form the concept of inclusive innovation, inclusive innovation emphasizes to make the BOP groups (the Base of the Pyramid, BOP) and TOP (TOP of the Pyramid, TOP) enjoy the equal employment opportunity and fair market participation, Improve their capacity for development, further alleviate their poverty and improve their standard of living. Such innovative ideas not only help to highlight social equity and justice (George,2012 [9]), but also help enterprises build new competitive advantages with new development logic and new resources and capabilities (Kelly, 2009 [10]). The discussion on responsible innovation originated from the "responsible development" proposed by the United States in 2003 for the field of nanoscience and technology (Owen, Macnaghten Stilgoe, 2012 [11]; Mei liang, Chen jin, li fujia, 2018), and Von Schomberg (2011) put forward "responsible research and innovation", holding that scientific and technological innovation should be ethically acceptable and meet social expectations. The eu's "horizon 2020 framework programme" formally introduced the concept of "responsible innovation", which is in contrast with four types of non-responsible innovation. That is, innovation that relies solely on technology, innovation that ignores ethical norms, innovation that simply relies on policy, innovation that ignores technology foresight and crisis prevention (Von Schomberg,2013 [12]).

From the above analysis, it can be seen that the view of innovation has gone through four stages: idea, elements, methodology and value orientation, stage of idea have solved the problem of "Can" , element phase addresses the question of "What to innovate"(What), phase methodology to solve the problem "How to innovate" (How), The value-oriented stage solves the problem of "Which innovation is needed" facing the society (Which). Before the three stages of the innovation 
view, function and position in the strategic analysis paradigm presented into the trend. However, innovation is subordinate to strategy and serves strategy, the strategy is the set of solutions in the environment that best conforms to the rational goals of the enterprise (Bundle of Solutions), and there is no fundamental response to the question of "why enterprises innovate" and "how to innovate" in a grand vision covering government, society, industry and enterprises. So it seems, innovation only the means of enterprise in order to achieve the rational goal, whether to promote industry together with the social welfare is uncertain. It is not even possible to rule out the possibility that innovation carried out by companies for their own benefit is not conducive to the welfare of industry and society. However, to be sure, in the evolution logic of the innovation view of "Can-WhatHow", the vitality generated by innovation is increasingly strong, which gradually lays the foundation for innovation to become a "relatively independent and complete theoretical system" in the management field. In the fourth stage, the view of innovation tries to respond to what values companies should hold in order to make meaningful innovations in the context of promoting the common welfare of society, such as inclusive innovation and responsible innovation. Unfortunately, as a new theory emerges, although it has provided important inspirations for the theoretical system construction of Leading Innovation, it has not summarized the micro mechanism of enterprise Leading Innovation.

\section{CONNOTATION}

"Innovation is the primary driving force for development". "Leading Innovation" and "strategic orientation" are two essentially different business evolution logics that are both interrelated and different from each other. Researchers have noticed that the difference of enterprise values (target) and the strategic, such as Xie Kehai a GREAT model (2018) argues that "financial health, through the values guide, the specialized service accelerate the progress of human society" of the enterprise can only be a "GREAT company", This kind of enterprise does not take financial pursuit as the fundamental goal, but seeks to promote the common welfare of human society, while strategy is the process of enterprise goal realization. These research results lay a solid foundation for the theory of "Leading Innovation" and are a beneficial supplement to the concept of innovation. As stated earlier, in view of innovation of the idea, element, methodology and value orientation of four stage, the view of innovation is to solve "Why should an enterprise innovate", "how should it innovate", "what kind of innovation is needed" and so on a series of propositions. Looked from the development of the view of innovation, innovation view increasingly requires enterprise development need to respond to the dual balance of the social value and enterprise value, the choice and implementation of enterprise strategy should be led by the innovation that promotes the common welfare of human society. On the surface these statements seem to make a distinction between "innovation-leading" and "strategy-oriented", but the deeper differences between the two need to be sorted out on a comparative basis.

The process from case situation to case discussion, is a complex process of step-by-step coding that follows objectivity and logic, this paper used case data from the survey, and then code it step by step when comparing with the traditional "strategic orientation", and concepts into a concept of "first order" (Guo Huibin, 2016) and "second order" (Berg, 2007). On this basis, gradually formed the core variables that distinguish "innovation guidance" from "strategic guidance", also become the concept of "Leading Innovation", as shown in Table 1. 
TABLE I. THE CORE VARIABLES OF THE CONNOTATION OF "LEADING INNOVATION"

\begin{tabular}{|c|c|c|c|}
\hline \multirow{2}{*}{ key variable } & \multicolumn{2}{|l|}{ Leading Innovation } & \multirow{2}{*}{$\begin{array}{c}\begin{array}{c}\text { Strategic } \\
\text { Orientation }\end{array} \\
\text { core feature }\end{array}$} \\
\hline & Certificate according to the case example & $\begin{array}{l}\text { The main } \\
\text { categories }\end{array}$ & \\
\hline Value & $\begin{array}{c}\text { From the "child prodigy washing machine" in } \\
1995 \text { to the "dual-direct-drive washing } \\
\text { machine" in } 2018 \text {, its research and } \\
\text { development design stems from the market } \\
\text { demand, which is value-oriented to solve the } \\
\text { market pain points and meet the needs of } \\
\text { users. }\end{array}$ & User demand & $\begin{array}{l}\text { Maximum } \\
\text { corporation } \\
\text { value }\end{array}$ \\
\hline Attitude & $\begin{array}{l}\text { "Now that demand has increased and clothes } \\
\text { are available in a variety of materials, but dry } \\
\text { cleaning is not guaranteed to be clean, this } \\
\text { calls for a third cleaning revolution. Air } \\
\text { washing machine, according to various } \\
\text { material drying temperature, humidity and } \\
\text { wind direction of the research, the washing } \\
\text { machine innovation, from the design and } \\
\text { technology to do a lot of changes. We } \\
\text { launched an air washing machine. There are } \\
\text { also washing machines that do not use } \\
\text { washing machines to reduce pollution. }\end{array}$ & $\begin{array}{l}\text { The core means } \\
\text { of fulfilling } \\
\text { social } \\
\text { responsibility }\end{array}$ & $\begin{array}{l}\text { One of the } \\
\text { means of } \\
\text { achieving } \\
\text { strategy }\end{array}$ \\
\hline Effect & $\begin{array}{l}\text { In the } 1980 \text { s, zhang ruimin said, "foreigners } \\
\text { only ration us to sell defective goods, why } \\
\text { can't we make them?" Which deeply reflects } \\
\text { the entrepreneur's national feelings. In July } \\
2018 \text {, two international standards, "framework } \\
\text { and general requirements of smart family } \\
\text { system" and "general requirements and } \\
\text { interoperability specifications of the Internet } \\
\text { of clothing", led by Haier, formally passed the } \\
\text { review of the institute of electrical and } \\
\text { electronic engineers and successfully } \\
\text { approved the project, which started to lead the } \\
\text { industry trend. }\end{array}$ & $\begin{array}{l}\text { Focus on the } \\
\text { industry and } \\
\text { social } \\
\text { contributions }\end{array}$ & $\begin{array}{l}\text { Focus on } \\
\text { competitive } \\
\text { advantage in } \\
\text { their own } \\
\text { industry }\end{array}$ \\
\hline Driving & $\begin{array}{l}\text { At Haier, you are the master, and you must do } \\
\text { everything by yourself. From the large } \\
\text { research team to the small product innovation, } \\
\text { under the integrated management model of } \\
\text { "Integrating Order with Personnel", we will } \\
\text { spontaneously keep up with the user's } \\
\text { demand. Innovation, continuous innovation, is } \\
\text { our culture." }\end{array}$ & It's a culture & $\begin{array}{c}\text { Driven by } \\
\text { institution and } \\
\text { mechanism }\end{array}$ \\
\hline
\end{tabular}

\section{A. Value orientation}

When Haier was developing "washing machines without washing powder" and "dual-drive washing machines", insight into the adverse effects of old washing machines and washing methods on the environment, and then, the product Innovation direction is only based on these market pain points that are not in line with "Green Innovation"to those with a "Green Innovation", fully integrated internal and external resources for product innovation. Such innovation behavior cannot be fully explained by the innovation behavior under the "strategic orientation", and the value orientation plays a crucial role in the innovation process. It can be said that the value orientation of "innovationleading" goes beyond the satisfaction of enterprises own interests and values, devotes itself to the dual balance between enterprises' own interests and the social interests, and attaches more importance to the realization of their own interests in the process of promoting social progress. In the practice of enterprise management, it is embodied as "user demand orientation", which takes solving market pain points and satisfying user demand as the logical starting point and value purposive of enterprise behavior. The fully absorb the concept of value during inclusive innovation (George, 2012) and responsibility innovation (Owen, Macnaghten Stilgoe, 2012). In contrast to "Leading Innovation", innovation in "strategic orientation" is only a means to realize strategy, while the choice of enterprise strategy is to maximize enterprise value based on internal and external environment. 
Among them, there are a number of well-known strategy formulation tools such as SWOT and Boston matrix.

\section{B. Attitude towards innovation}

In the strategy-oriented paradigm, innovation is a necessary and insufficient means to realize strategy. Strategy plays a guiding role in the innovation mode, and innovation satisfies the internal needs of enterprises to the greatest extent. However, in the paradigm of innovationleading, such issues as "whether to innovate" and "what kind of innovation to choose" break through the boundary of discussing innovation within enterprises, and attach more importance to the positive impact of innovation on industry, society, nation and country, and regard innovation as the core means to fulfill social responsibilities.

\section{Effect}

The effect of strategic orientation is the establishment of its own competitive advantage in the industry, the purpose is to achieve the competition strategy, While the effect of Leading Innovation is focused on the contribution to the industry and society. Such as Haier successfully passed the international standard evaluation of smart home and Internet of clothing in July 2018, thus accelerating the internationalization of Domestic Electric Appliances Trade. It will improve the overall competitiveness of China's home appliance industry in the world's home appliance industry.

\section{Driving}

The elements including innovation are driven by the system and mechanism in strategic orientation, but the Leading Innovation is more dependent on the innovation culture consciousness of the enterprise management and employees. For example, Haier has formed a culture of Keep up with needs of users, observing industry trends and constantly promoting product innovation.

\section{Conclusions}

The concept of Leading Innovation is tentatively defined in this paper, It is mainly divided into the following four dimensions: First, Value. The value orientation of innovation-leading is beyond the satisfaction of enterprises' own interests and values. It is committed to the dual balance between enterprises' own interests and the promotion of social interests, and attaches more importance to the realization of their own interests during the process of promoting social progress. Second, Attitude. Leading Innovation leads innovation to a higher level, which requires a stronger sense of social responsibility as the guidance, in an innovative way to "guide, leading" the choice and implementation of corporate strategy, so as to achieve positive interaction between the value of enterprise benefits and social value, promote the progress of human society. Third, Effect. In addition to building sustainable competitive advantages of enterprises, the effect of innovation-leading is more important because of its contribution to industrial technology and social progress. Fourth, Driving. The driving force of innovation is innovation culture.

The authors greatly acknowledge the sponsorship provided by National Nature Science Foundation of
China(71572177), Tianyou Youth Talent Lift Program of Lanzhou Jiaotong University. Haibing Liu is correspondence author of this paper.

\section{REFERENCES}

1. $\mathrm{X} . \mathrm{Wu}, \mathrm{Y} . \mathrm{Fu}, \mathrm{D} . \mathrm{Wu}$ and L. Lei, "How Do Latecomers Transform from Catch-up to Beyond Catch-up?" Beijing, Management World, vol.2, 2019, pp.151-167+200.

2. H. B. Liu and Q. R. Xu, "Latecomer firms strategy evolution,innovation paradigm and capabilities evolution," Beijing, vol. 36, 2018, pp.1442-54.

3. G. Dosi, "Technological Paradigms and Technological Trajectories," Research Policy, vol.11, 1982, pp.147-162.

4. Q. R. Xu, “Comprehensive innovative management: theory and practice," Beijing: science press, 2007.

5. C. M. Christensen, M. E. Raynor. "Why Hard-nosed Executives Should Care about Management Theory," Harvard business review,vol.9, 2003, pp.66-74.

6. A. B. Hargadon. "How Breakthroughs Happen:The Surprising Truth about How companies Innovate," Boston:Harvard Business School Press, 2003.

7. G. O'Connor, "Major Innovation as a Dynamic Capability:A Systems Approach," Journal of Product Innovation Management, vol. 2, 2008, pp.313-330.

8. H. W. Chesbrough, “Open Innovation:The New Imperative for Creating and Profiting from Technology" Boston:Harvard Business School Press, 2003.

9. G. George, A. M. Mcgahan and J. Prabhu, "Innovation for Inclusive Growth:Towards a Theoretical Framework and a Research Agenda," Journal of Management Studies, vol.4, 2012, pp.661-683.

10. M. Kelly. "Not Just for Profit," Strategy\&Business, vol.10, 2009,pp.9-19.

11. R. Owen, P. Macnaghten and J. Stilgoe, "Responsible Research and Innovation: From Science in Society to Science for Society,with Society," Science and Public Policy, vol.6, 2012, pp.751-760.

12. R. Von Schomberg, "A vision of responsible research and innovation," Responsible Innovation, 2013, Chapter 3, pp.51-74. 